\title{
Optimal design of CMOS current mode instrumentation amplifier using bio-inspired method for biomedical applications
}

\author{
Issa Sabiri $^{1}$, Hamid Bouyghf ${ }^{2}$, Abdelhadi Raihani ${ }^{1}$, Brahim Ouacha ${ }^{2}$ \\ ${ }^{1}$ Laboratory of Systems, Signals and Artificial Intelligence, ENSET, University Hassan II, Casablanca, Morocco \\ ${ }^{2}$ Laboratory of Electronics, Energy, Automatics and Data Processing, Faculty of Sciences and Techniques, University Hassan II, \\ Casablanca, Morocco
}

\begin{tabular}{l} 
Article Info \\
\hline Article history: \\
Received May 31, 2021 \\
Revised Oct 14, 2021 \\
Accepted Nov 30, 2021 \\
\hline
\end{tabular}

Keywords:

Active resistor

CMOS conveyors

CMRR

Instrumentation amplifier

Metaheuristics

\begin{abstract}
Analog integrated circuits for biomedical applications require good performance. This paper presents an instrumentation amplifier (IA) design based on three complementary metal oxide semiconductor (CMOS) conveyors with an active resistor. This circuit offers the possibility to control the gain by voltage and current. We have designed the IA to minimize the parasitic resistance $(\mathrm{Rx})$ with large bandwidth and high common mode rejection ratio (CMRR) using the artificial bee colony algorithm (ABC). The topology is simulated using $0.35 \mu \mathrm{m}$ CMOS technology parameters. The optimization problem is represented by an objective function that will be implemented using MATLAB script. The results were approved by the simulation using the advanced design system (ADS) tool. The simulation results were compared to the characteristics of some other instrumentation amplifiers exsisting in the literature. The circuit has a higher CMRR than other topologies.
\end{abstract}

This is an open access article under the CC BY-SA license.

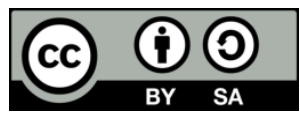

\section{Corresponding Author:}

Issa Sabiri

Laboratory of Systems, Signals and Artificial Intelligence, ENSET, University Hassan II

Casablanca, Morocco

Email: issa.sabiri@etu.fstm.ac.ma

\section{INTRODUCTION}

An instrumentation amplifier (IA) is commonly used in industrial and medical applications with reduced power. A low voltage signal must be processed in the presence of common-mode voltages and considerable direct current (DC) potentials. The conventional instrumentation amplifier, as shown in Figure 1, consists of three operational amplifiers and the network of resistances.

Acquiring, transferring, and processing biopotential reliably are essential tasks in biomedical systems. These systems impose demanding specifications that usually increase the cost of the devices. The circuits used for processing biomedical signals must guarantee patient safety and the rejection or attenuation of any interfering signal [1]. Therefore, building high-performance blocks, such as low noise amplifiers and analog filters, are requirements for improving system performance [2]. For the implementation of biopotential acquisition systems, some of the most critical design considerations are low noise voltage and current levels, low harmonic distortion, reduced area, and low power consumption [3], [4]. A biomedical signal acquisition system, such as in Figure 2, consists of electrodes, amplifiers, low-pass filter (LPF), sample, socket (S/H), and analog-to-digital converter (ADC) [5], [6].

The detection of these signals is essential because they usually have very low amplitude with considerable noise levels. The majority of these signals have a very low-frequency range, generally less than $1 \mathrm{khz}$ [7]. Instrumentation amplifiers are used to remove any unwanted noise and produce the amplification 
adapted to the desired signal. Common mode rejection ratio (CMRR) is considered the main parameter of instrumentation amplifiers.

Currently, many of the physiological processes are continuous to sustain human life. The instrumentation amplifier is the basis of most electrocardiography (ECG), electroencephalography (EEG), and electromyography (EMG) acquisition systems [8], [9]. Voltage mode instrumentation amplifiers have high accuracy. In the current mode version, the CMRR is independent of the mismatching of the resistors.

Several documents show the topologies presented in the second-generation current conveyor (CCII). In 1989 [10], the current mode instrumentation amplifier based on current carriers was presented. The CCII is a device used to provide a wide operating frequency a bias current can electronically control it in numerous current mode applications [11], [12]. The disadvantage of electronic circuits based on the CCII is the parasitic resistance that polarization can control. This resistance is directly proportional to the mobility of the surface $(\mu)$, to the capacity of the oxide (Cox), and its relation to channel width and length (W/L) for complementary metal oxide semiconductor (CMOS) technology. The symbol of CCII is shown in Figure 3.

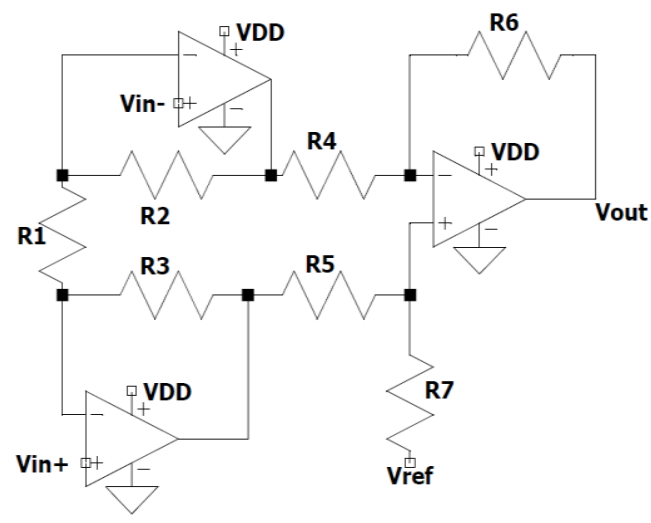

Figure 1. Conventional instrumentation amplifier

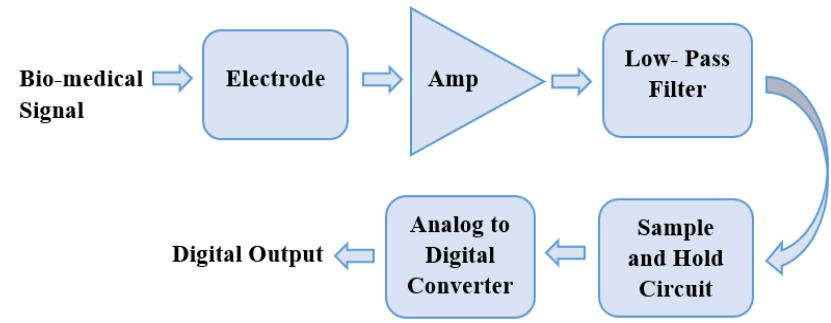

Figure 2. The electronic system for detecting physiological signal blocks

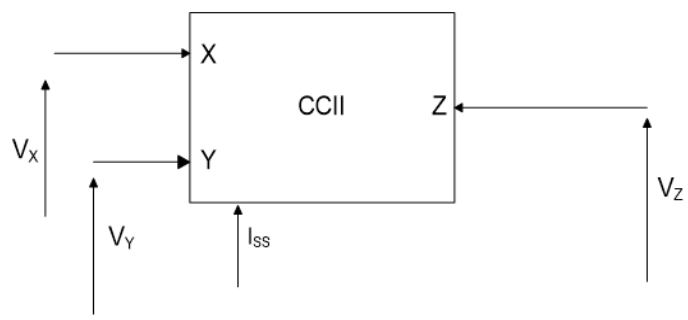

Figure 3. Second-generation current conveyor

However, nature is a vibrant field of inspiration for artificial intelligence by developing algorithms (metaheuristics) [13] with a great capacity to solve complex problems in which most traditional strategies have severe difficulties and limitations [14]. Optimization based on swarm intelligence (SI) is a very recent family of metaheuristic algorithms inspired by nature [15], [16]. Its principle is based on the intelligent comportment of the species during the search and exploitation of the food [17]. Thus, these species possessing a very high communication capacity by collaborating can solve very complex and challenging problems. Reliable, efficient, and robust optimization techniques are in high demand in all engineering 
domains, especially in electronics applied to biomedical data processing. We focus in this article on the use of bio-inspired method, specifically artificial bee colony, for the optimal design of CMOS current-mode instrumentation amplifier using bio-inspired method for biomedical applications. This paper is structured as follows. An overview of artificial bee colony is highlighted in section 2. The proposed instrumentation amplifier is presented in section 3. Section 4 presents the results and discussion. Eventually, conclusion is given in section 5 .

\section{OVERVIEW OF ARTIFICIAL BEE COLONY ALGORITHM (ABC)}

The artificial bee colony algorithm (ABC) was introduced by Karaboga in 2005 [18]. The ABC algorithm is formed by observing real bees' activities and behavior as they seek nectar resources and share the number of resources with other bees [19]. The ABC algorithm defines a set of operations that resemble some characteristics of the behavior of the bees. Each solution within the search space includes a set of parameters representing the positions of the food sources. The value of "affinity" (provided by the objective function) refers to the food source's quality. In general, the optimization process mimics the search for bees for important food sources resulting in a process analogous to finding optimal solutions [20], [21].

In the $\mathrm{ABC}$, every food source is in the D-dimensional search area and represents a potential solution to the optimization problem. The quantity of nectar in the food source is assumed to be a food source's fitness value. In general, the number of bees employed and the number of bees as spectators is equal and is identical to the number of food sources. Each employed bee is a food source member and charged with the corresponding food source's operation. Then, the employed bees communicate the nectar information to the spectator bees in the "dance area". The spectator bees wait in the hive and decide which food source to exploit depending on the employed bees' information.

In this case, more beneficial food sources will have a more significant probability of being selected by the spectator bees. In the initial step of the ABC algorithm, the initial solutions are generated randomly in the specific range of variables $x_{i}(i=1,2, \ldots, w)$ [22]. Next, each employed bee identifies the new sources whose quantities are equal to half of the total sources. In (1) is used to determine a new source [23].

$$
V_{i j}=x_{i j}+\varphi_{i j}\left(x_{i j}-x_{k j}\right)
$$

In (1), $k \in\{1,2, \ldots, N\}$ and $j \in\{1,2, \ldots, D\}$ are randomly selected indices. While $k$ it is randomly determined, it should be different to $i$ and $\varphi_{i j}$ random between 0 and 1 . This parameter controls the adjacent food sources production and visually compares two food positions $x_{i j}$ by a bee. After each source position candidate $V_{i j}$ is produced and then evaluated by the artificial bee, its performance is compared to the last one. If the new food has nectar equal to or superior to that of the ancient source, it is used to replace the old memory. In the opposite case, the ancient one is conserved in the memory. In the next step, the onlooker bees choose a food source with the probability mentioned in (2) [24].

$$
P_{i}=\frac{f i t_{i}}{\sum_{j=1}^{w N} f i t_{j}}
$$

The adequacy value $f i t_{i}$ of the solution $\mathrm{i}$, which is proportional to the quantity of nectar from the food source in the position, is the number of food sources, which is the same as the number of bees employed. The scout bees are very responsible for the random searches in every colony. The scout bees do not use previous knowledge and facts when searching for nectar sources, so their searches are entirely random. The scout bees are selected from the bees employed according to the boundary parameters. If a solution that indicates a source is not achieved with a particular number of tests, then that source is rejected. The bee from this source selects the new head as the scout bee. The number of inputs/outputs of a source is determined by the "limit" parameter. The recognition of a new source of a scout bee is given in (3) [25].

$$
X_{i j}=X_{j}^{\min }+\left(X_{j}^{\max }-X_{j}^{\min }\right) * \operatorname{rand}(0,1)
$$

Where $X_{j}^{\min }$ and $X_{j}^{\max }$ are the minimum and maximum limits of the parameter to be optimized.

In the $\mathrm{ABC}$ algorithm, the termination criterion is generally based on the number of iterations. Usually, an optimization algorithm's stopping criteria are based on the maximum number of iterations or the maximum error between two successive iterations. Consequently, the stopping criterion for the proposed $\mathrm{ABC}$ is based solely on the maximum number of iterations. In general, the $\mathrm{ABC}$ algorithm process can be summarized, as shown in Figure 4 [26], [27]. 


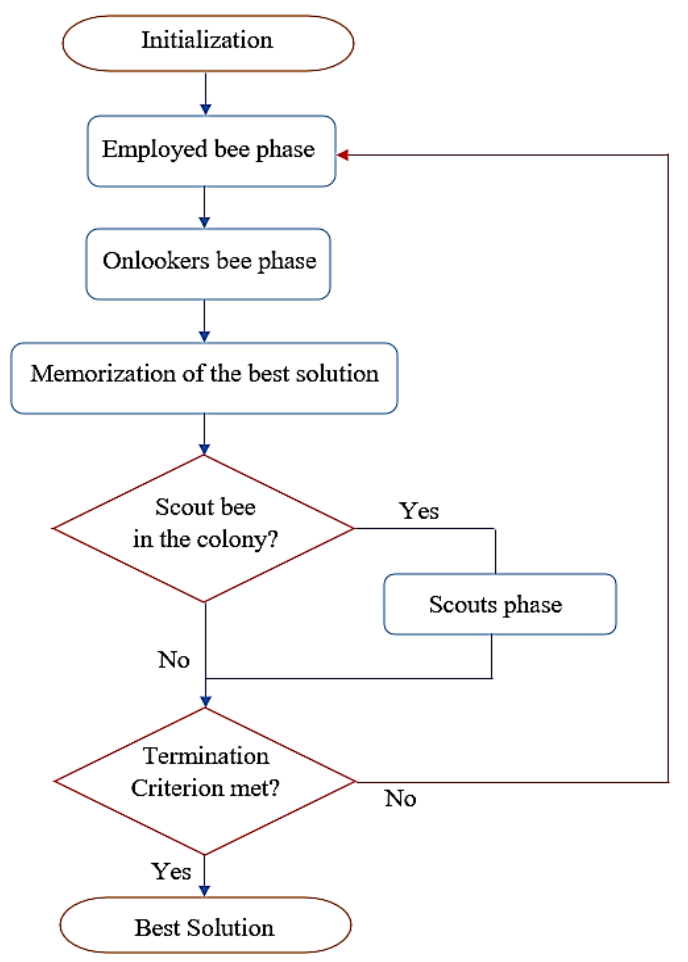

Figure 4. Flowchart of the basic model of the ABC algorithm

\section{PROPOSED INSTRUMENTATION AMPLIFIER}

\subsection{CMOS second-generation current convoyors}

Second generation current conveyors are among the best-known analog blocks in current mode [28]. The CCII composed of three blocks terminal active CMOS circuits. The matrix below presents the characteristic of CCII:

$$
\left(\begin{array}{l}
I_{y} \\
V_{x} \\
I_{z}
\end{array}\right)=\left(\begin{array}{ccc}
0 & 0 & 0 \\
1 & R_{X} & 0 \\
0 & 1 & 0
\end{array}\right) \cdot\left(\begin{array}{l}
V_{y} \\
I_{x} \\
V_{z}
\end{array}\right)
$$

As showing in the Figure 3, where the port $\mathrm{X}$ and $\mathrm{Y}$ of the CCII are the input of the circuit, the parasitic resistance $\mathrm{R}_{\mathrm{X}}$ on this terminal is given by:

$$
R_{x}=\frac{1}{2 g_{m}}=\frac{1}{\sqrt{8 K_{n} I_{S S}}}
$$

where $\mathrm{g}_{\mathrm{m}}$ is the transconductance of the CMOS transistor and $\mathrm{K}_{\mathrm{n}}$ is the physical parameter of the metal-oxide semiconductor transistor. They can be expressed as:

$$
\begin{aligned}
g_{m} & =\sqrt{2 K_{n} I_{S S}} \\
K_{n} & =\mu_{n} C_{o x}\left(\frac{W}{L}\right)
\end{aligned}
$$

where $\mathrm{C}_{\mathrm{ox}}$ is the gate capacity per unit area and $\mu \mathrm{n}$ is the electronic mobility of the PMOS transistor. The parasitic resistance $R_{x}$ depends as well on the adaptation of the $g_{m}$ values, but this parasitic resistance is available and adjustable even if the values do not correspond due to variations in the process.

\subsection{Theoretical study}

The diagram of the proposed instrumentation circuit is shown in the Figure 5. The instrumentation amplifier composed of three current conveyors and an active resistor structure based on MOS transistors. The active resistor format is realized by a parallel connected matched pair of MOS transistors, M1 and M2 as showing in the Figure 6. 
Figure 6 illustrates the active resistor circuit. The voltage $\mathrm{V}_{\mathrm{C}}$ is used to control the active resistance. The drain current for each transistor can be obtained from the circuit according to the following expressions:

$$
\begin{aligned}
& I_{D 1}=\mu_{n} C_{o x}\left(\frac{W}{L}\right)\left[\left(V_{A}-V_{t h}\right) V_{A}-\frac{V_{A}^{2}}{2}\right] \\
& I_{D 2}=\mu_{n} C_{o x}\left(\frac{W}{L}\right)\left[\left(V_{C}-V_{t h}\right) V_{A}-\frac{V_{A}^{2}}{2}\right]
\end{aligned}
$$

Therefore, the resistance of the active resistor $\mathrm{R}_{\mathrm{A}}[29]$ can be expressed as:

$$
R_{A}=\frac{1}{\mu_{n} C_{o x}\left(\frac{W}{L}\right)\left(V_{C}-2 V_{t h}\right)}
$$

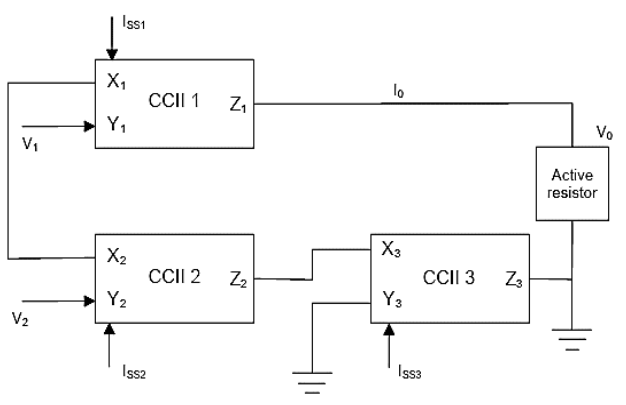

Figure 5. Proposed instrumentation amplifier

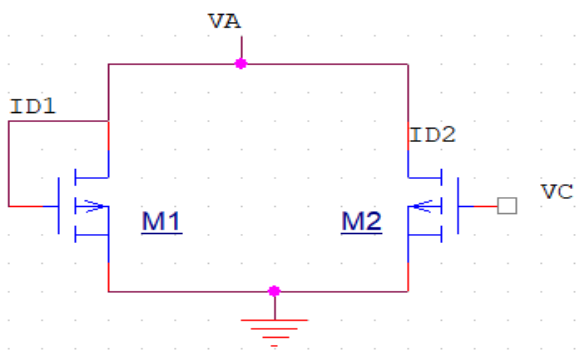

Figure 6. Active resistor circuit

The control voltage $V_{C}$ makes it possible to adjust the active resistance $R_{A}$ and as shown in the matrix (1) the current of port $\mathrm{X}$ is equal to the current of port $\mathrm{Z}$ which makes the proposed instrumentation amplifier provides a current with the following expression:

$$
I_{0}=\frac{V_{1}-V_{2}}{R_{x 1}+R_{x 2}+R_{x 3}}
$$

The voltage at port X, as shown in Figure 7, can be expressed as:

$$
\begin{aligned}
& V x_{1}=K_{1} V_{1} \\
& V x_{2}=K_{2} V_{2} \\
& V x_{3}=K_{3} V_{3}
\end{aligned}
$$

By varying the bias current of the conveyors and the control voltage of the active resistance, the differential gain of the IA can be controlled. The parasitic resistance can be adjusted by a bias current and that the active resistance can also be adjusted by the control voltage. The current and voltage tracking error between ports $\mathrm{X}-\mathrm{Z}$ and ports $\mathrm{X}-\mathrm{Y}$ can be expressed as follows:

$$
\begin{aligned}
& \alpha=1-\varepsilon_{I} \\
& K=1-\varepsilon_{V}
\end{aligned}
$$

Where $\alpha$ and $K$ are the current and voltage transfer gains and $\varepsilon_{\mathrm{I}}$ and $\varepsilon_{\mathrm{V}}$ are the current and voltage transfer errors of the conveyors, respectively. At port $\mathrm{Z}$, the current can be expressed as:

$$
I_{Z}=\alpha I_{X}
$$

The output voltage will be:

$$
V_{0}=\frac{R_{A}}{R_{x 1}+R_{x 2}+R_{x 3}}\left(V_{1}-V_{2}\right)
$$

\subsection{Real instrumentation amplifier}

Figure 8 shows the real model of the proposed instrumentation amplifier. We can calculate the resulting current $i_{\mathrm{x}}$ as follows: 


$$
I_{X}=\frac{V x_{1}-V x_{2}-V x_{3}}{3 R_{x}}
$$

From (12), (13), (14) and (19) we obtain:

$$
I_{0}=\alpha I_{X}=\alpha \frac{K_{1} V_{1}-K_{2} V_{2}}{3 R_{X}}
$$

The output voltage $\mathrm{V}_{0}(\mathrm{~s})$ can be written as follows:

$$
V_{0}(s)=I_{0}\left(R_{A} / / \frac{1}{s c_{b}}\right)
$$

where $C_{b}=C_{Z}+C_{A}$ are the capacity of the output node, which is parallel to the resistance $R_{A}$ as showing in the Figure 7 thus:

$$
V_{0}(s)=\alpha \frac{\left(K_{1} V_{1}-K_{2} V_{2}\right) R_{A}}{3 R_{x}\left(1+s C_{b} R_{A}\right)}
$$

We assume that $\mathrm{V}_{1}=\mathrm{V}_{2}=\mathrm{V}_{3}=\mathrm{V}_{\mathrm{Cm}}$, the gain in common mode can be obtained as follows:

$$
A_{C m}=\frac{V_{0}}{V_{C m}}=\alpha \frac{\left(K_{1}-K_{2}\right) R_{A}}{3 R_{x}\left(1+s C_{b} R_{A}\right)}
$$

For ideal current conveyors, $\alpha=\mathrm{K}_{1}=\mathrm{K}_{2}=1$, the differential output gain $\mathrm{A}_{\mathrm{dm}}$ can be written:

$$
A_{d m}=\frac{R_{A}}{3 R_{x}} \frac{1}{\left(1+s C_{b} R_{A}\right)}
$$

From the (24), the voltage gain is controllable by $R_{A} / 3 R_{x}$.

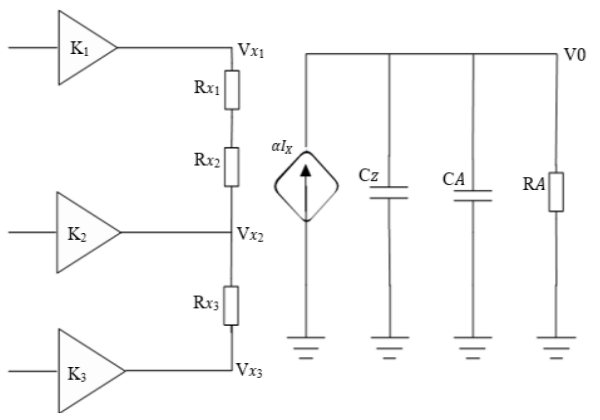

Figure 7. Error equivalent circuit of instrumentation amplifier

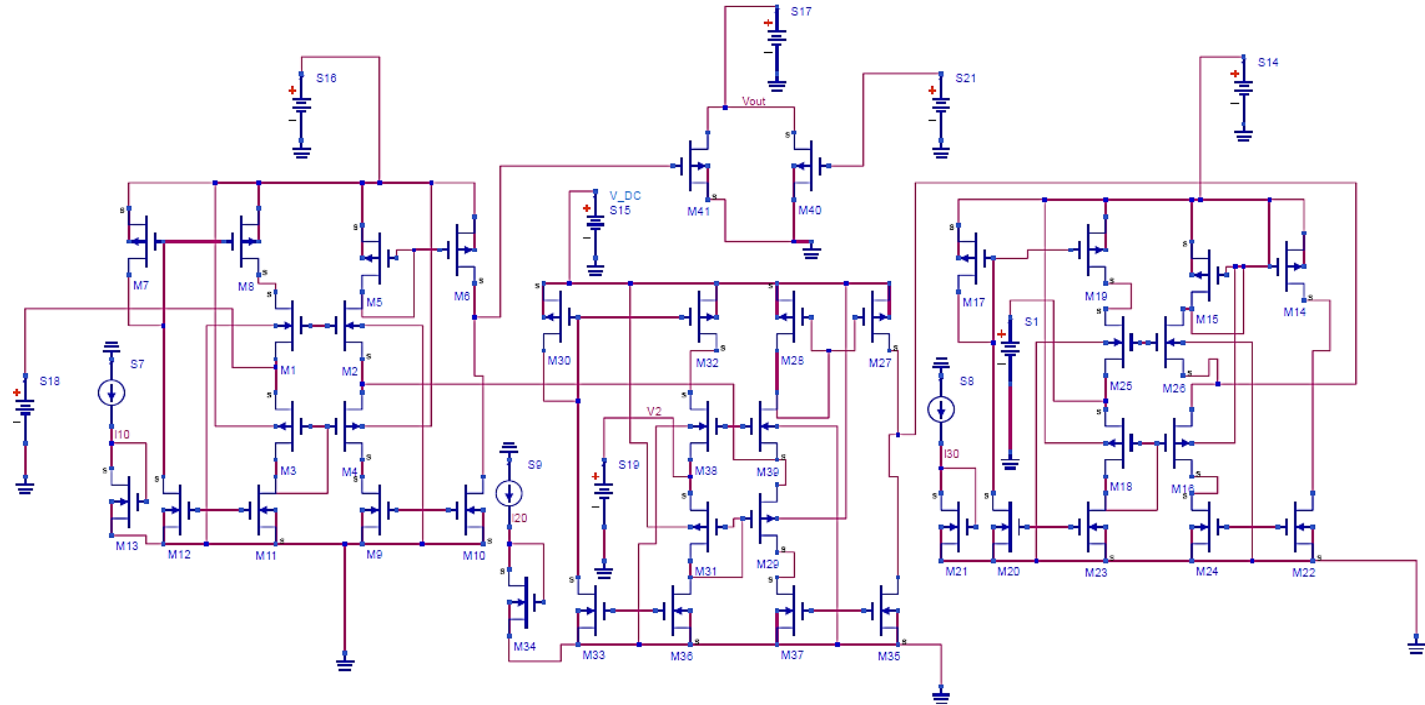

Figure 8. Real model of instrumentation amplifier 


\section{RESULTS AND DISCUSSION}

Our problem is to minimize the resistance and maximize the cutoff frequency. We will consider our optimization problem as a minimization problem, where our objective function will be written as follows:

$$
O F=\alpha R x+\beta t c i
$$

where $\mathrm{t}_{\mathrm{ci}}=1 / \mathrm{f}_{\mathrm{ci}}$ and $\alpha+\beta=1$.

A factor $\alpha=\beta=0.5$ means that there will be no favoritism when optimizing our objective function. Neither of the two parameters will be considered more important than the other. Using MATLAB, we can draw our objective function $\mathrm{OF}=0.5^{*}\left(\mathrm{R}_{\mathrm{x}}+\mathrm{t}_{\mathrm{ci}}\right)$. The factor 0.5 means that we want to optimize each of the resistance and the frequency of power failure by giving them the same importance. When we talk about optimizing the FO function, we are talking about minimization, hence the convergence of the function towards 0 . In this case, the function could reach a power $*-10^{*}$ as showing in Figure 9 . We note that our parasitic resistance, during the optimization of the OF, as showing in the Figure 10 Rxmin converges to stabilize on a value of $457.745 \Omega$. Table 1 summarizes the optimization of parasitic resistance and cutoff frequency, the values of our parameters Wp and Wn for the MOS transistors' channel lengths (Ln and Lp) fixed.

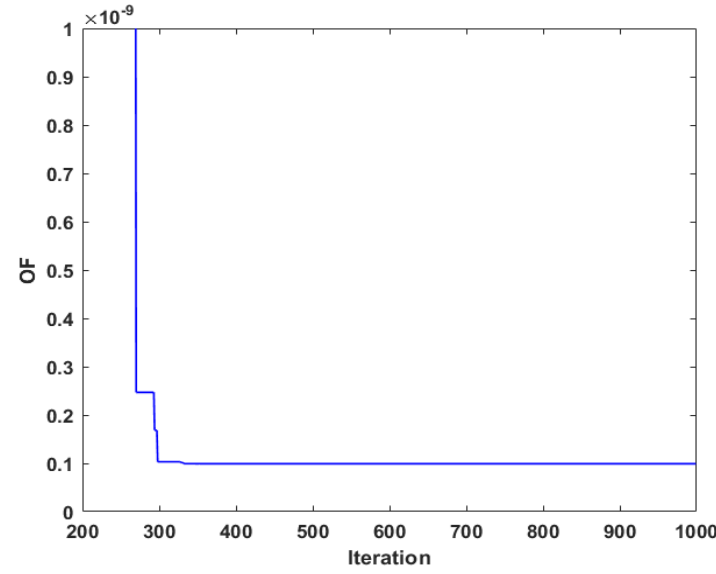

Figure 9. Objectif function

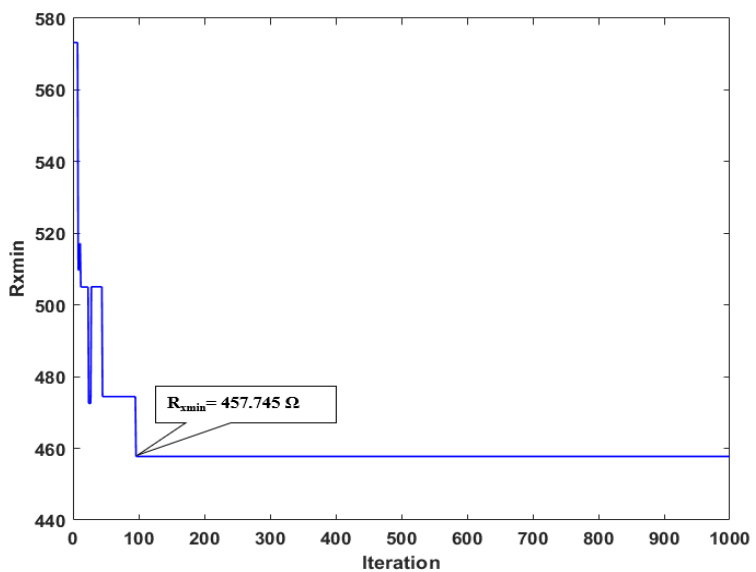

Figure 10. Optimal result of $\mathrm{R}_{\mathrm{x}}$

Table 1. Optimal sizes of transistor dimensions

\begin{tabular}{cccc}
\hline $\mathrm{L}_{\mathrm{n}}(\mu \mathrm{m})$ & $\mathrm{L}_{\mathrm{p}}(\mu \mathrm{m})$ & $\mathrm{W}_{\mathrm{p}}(\mu \mathrm{m})$ & $\mathrm{W}_{\mathrm{n}}(\mu \mathrm{m})$ \\
\hline 0.58 & 0.35 & 36 & 19.77 \\
\hline
\end{tabular}

To confirm the results obtained, we will simulate the design using the advanced design system (ADS) software. The circuit in Figure 8 simulated with the parameters of $0.35 \mu \mathrm{m}$ CMOS technology to verify the proposed circuit's performance with a supply voltage of $3.8 \mathrm{~V}$. The ISS chose at $90 \mu \mathrm{A}$ because the amplifier's gain is practically constant with ISS values higher than $90 \mu \mathrm{A}$. As showing in Figure 11(a), Rxmin stabilizes on a value of $431.56 \Omega$. The bandwidth is showing in Figure 11(b) with a $1.22 \mathrm{GHz}$ value of cutoff frequency. The CMRR of the proposed circuit has been examined and found that it is dependent on both the voltage transfer error $\varepsilon_{V}$ and current transfer error $\varepsilon_{\mathrm{I}}$.

The CMRR frequency response of the instrumentation amplifier is shown in Figure 12. We observe that the CMRR value of the instrumentation amplifier is very significant. The CMRR obtained by the simulation was $182.070 \mathrm{~dB}$ at $10 \mathrm{~Hz}$, which shows the importance of the circuit in biomedical applications, especially in the acquisition of physiological signals. A comparison between the proposed circuit and those of different studies is given in Table 2.

Table 2. Comparison between same instrumentation amplifier characteristics

\begin{tabular}{cccccc}
\hline Ref. & Supply Voltage & CMRR $(\mathrm{dB})$ & Control Function & Techno. & Passive Component \\
\hline$[29]$ & $2.5 \mathrm{~V}$ & 147 & Current & BJT & No \\
{$[30]$} & $2.8 \mathrm{~V}$ & 76 & Passive resistor & BJT & Yes \\
{$[11]$} & $3.3 \mathrm{~V}$ & 142 & Voltage or current & CMOS & No \\
This work & $3.8 \mathrm{~V}$ & 182.070 & Voltage or current & CMOS & No \\
\hline
\end{tabular}




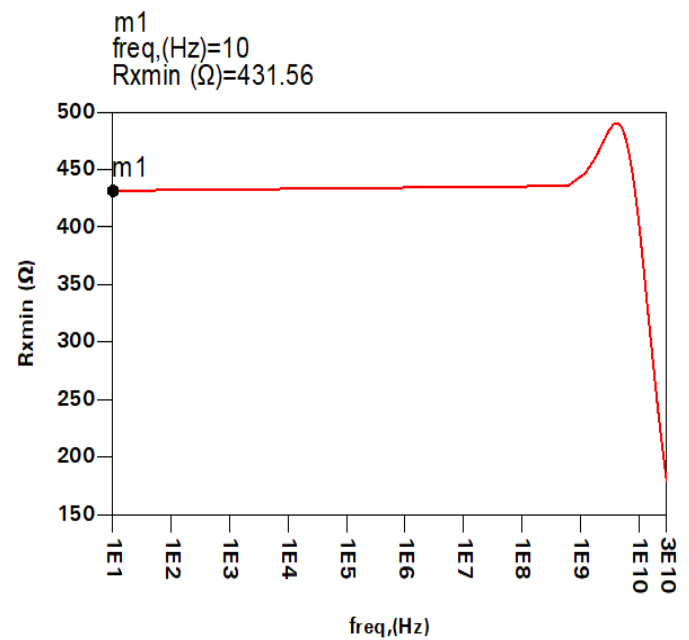

(a)

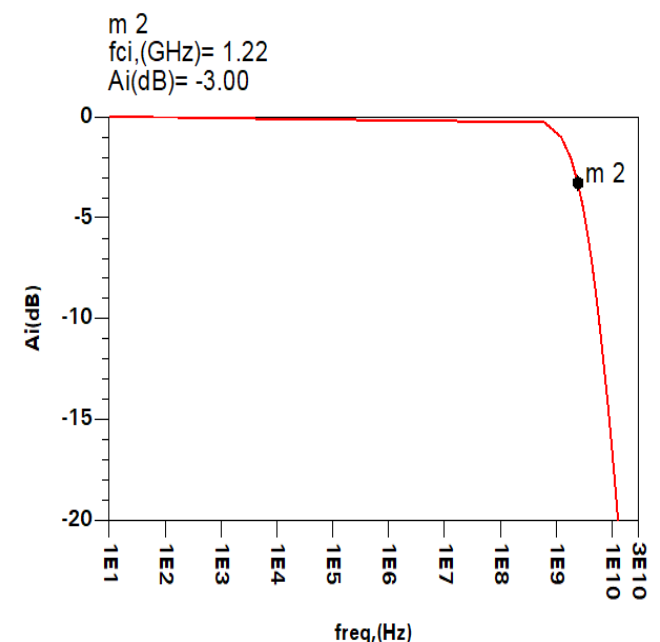

(b)

Figure 11. Simulation of (a) Rx using ADS tools and (b) Ai using ADS tools

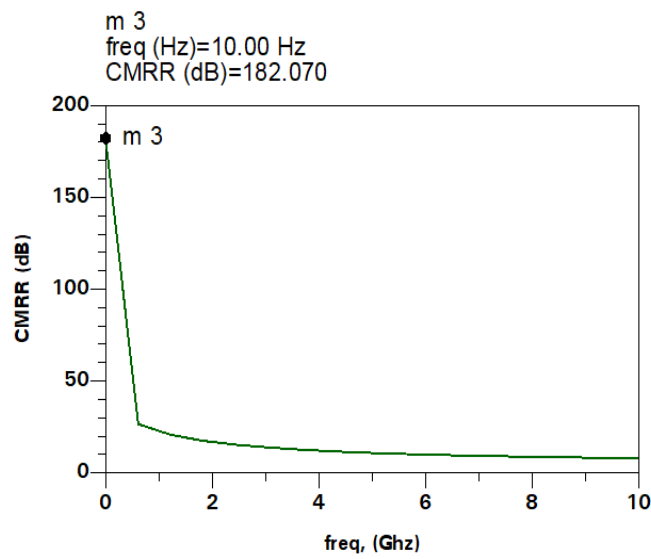

Figure 12. Result of CMRR simulation

\section{CONCLUSION}

In this study, an optimum design for an instrumentation amplifier is used, which consists of three current conveyors and has no passive components, which is attractive for medical applications. The proposed circuit was simulated using an ADS simulation program. The simulation results were compared to the properties of some other instrumentation amplifiers existing in the published papers. The circuit has an important CMRR than other works.

\section{REFERENCES}

[1] P. E. Allen and D. R. Holberg, "CMOS Analog Circuit Design," 2nd Ed. New York: Oxford University Press, 2002.

[2] G. Vasilescu, "Electronic Noise and Interfering Signals Principles and Electronic Noise and Interfering Signals. Principles and Applications," Springer, 2006.

[3] W. M. E. A. W. Jusoh, and S. H. Ruslan, "Design and analysis of current mirror OTA in $45 \mathrm{~nm}$ and $90 \mathrm{~nm}$ CMOS technology for bio-medical application," Bulletin of Electrical Engineering and Informatics, vol. 9, no. 1, pp. 221-228, 2020, doi: 10.11591/eei.v9i1.1860.

[4] W. M. E. A. W. Jusoh, S. H. Ruslan, N. Ahmad, W. M. Jubadi, and R. Sanudin, "Comparative study of symmetrical OTA performance in $180 \mathrm{~nm}, 130 \mathrm{~nm}$ and $90 \mathrm{~nm}$ CMOS technology," Indonesian Journal of Electrical Engineering and Computer Science, vol. 14, no. 1, pp. 230-240, 2019, doi: 10.11591/ijeecs. v14.i1. pp230-240.

[5] M. W. Gifari, H. Zakaria, and R. Mengko, "Design of ECG Homecare:12-lead ECG acquisition using single channel ECG device developed on AD8232 analog front end," Int. Conf. Electrical Engineering and Informatics (ICEEI), Denpasar, 2015, pp. 371-376, doi: 10.1109/ICEEI.2015.7352529.

[6] M. H. Nornaim, N. A. Abdul-Kadir, F. K. Che Harun, and M. A. Abdul Razak, "A Wireless ECG Device with Mobile Applications for Android," 7th International Conference on Electrical Engineering, Computer Sciences and Informatics (EECSI), Proc. EECSI 2020-1-2 October 2020, doi: 10.23919/EECSI50503.2020.9251871. 
[7] A. Goel and G. Singh, "A novel Low Noise High Gain CMOS Instrumentation Amplifier for Biomedical Applications," International Journal of Electrical and Computer Engineering, vol. 3, no. 4, pp. 516-2523, August 2013.

[8] S. Joshi, V. Thaker, A. Amaravati, M. Shojaei-Baghini, "low-power low-noise analog signal conditioning chip with on-chip drivers for healthcare applications," Microelectron. J., vol. 43, pp. 828-837, 2012, doi: 10.1016/j.mejo.2012.06.008.

[9] R. Harrison and C. Charles, "A low-power low-noise CMOS amplifier for neural recording applications," IEEE Journal of SolidState Circuits, vol. 38, no. 6, pp. 958-965, June 2003, doi: 10.1109/JSSC.2003.811979.

[10] S. J. G. Gift, B. Maundy, and F. Muddeen, "High-performance current-mode instrumentation amplifier circuit," International Journal of Electronics, vol. 97, no. 11, pp. 1015-1024, 2007, doi: 10.1080/00207210701751188.

[11] H. Ercan, S. Tekin, and M. Alçi, "Voltage- and current-controlled high CMRR instrumentation amplifier using CMOS current conveyors," Turkish Journal of Electrical Engineering and Computer Sciences, vol. 20, pp. 547-556, 2012, doi: 10.3906/elk-1011-939.

[12] M. Dorigo and T. Stützle, "The Ant Colony Optimization Metaheuristic: Algorithms, Applications, and Advances," Handbook of metaheuristics, 2003, Springer.

[13] S. Abi, H. Bouyghf, B. Benhala, and A. Raihani, "An Optimal Design of a Short-Channel RF Low Noise Amplifier Using a Swarm Intelligence Technique," Embedded Systems and Artificial Intelligence, vol. 1076, pp. 143-153, 2020, doi: 10.1007/978-981-150947-6 14.

[14] X. S. Yang, "A New Metaheuristic Bat-Inspired Algorithm," Nature Inspired Cooperative Strategies for Optimization (NICSO), pp. $65-74,2010$, doi: 10.1007/978-3-642-12538-6 6

[15] D. Karaboga, "An idea based on honeybee swarm for numerical optimization," Tech. Rep. TR06, Erciyes University, Engineering Faculty, Computer Engineering Department, 2005.

[16] B. Benhala, P. Pereira, and A. Sallem, "Focus on Swarm Intelligence Research and Applications," Nova Science Publishers, 2017.

[17] W. L. Chang, D. Z. Zeng, R. C. Ching, and S. Guo, "An artificial bee colony algorithm for data collection path planning in sparse wireless sensor networks," International Journal of Machice Learning \& Cybernetics, vol. 6, no. 3, pp. 375-383, 2015, doi: $10.1007 / \mathrm{s} 13042-013-0195-\mathrm{z}$

[18] C. Ozturk and D. Karaboga, "Classifications by neural networks and clustering with artificial bee colony (ABC) algorithm," Proceedings of the 6th International Symposium on Intelligent and Manufacturing Systems, Features, Strategies and Innovation, Sakarya, Turkey, 2008

[19] D. Karaboga and C. Ozturk, "A novel clustering approach: Artificial Bee Colony (ABC) algorithm," Applied soft computing, 2011 - Elsevier, vol. 11, no. 1, pp. 652-657, January 2011, doi: 10.1016/j.asoc.2009.12.025.

[20] S. Wang et al., "Feed-forward neural network optimized by hybridization of PSO and ABC for abnormal brain detection," Int. J. Imaging Syst. Technol., vol. 25, pp. 153-164, 2015, doi: 10.1002/ima.22132.

[21] V. H. Ahgajan, Y. G. Rashid, and F. M. Tuaimah, "Artificial bee colony algorithm applied to optimal power flow solution incorporating stochastic wind power," International Journal of Power Electronics and Drive System (IJPEDS), vol. 12, no. 3, pp. 1890-1899, September 2021, doi: 10.11591/ijpeds.v12.i3.pp1890-1899.

[22] D. Karaboga and B. Akay, "A comparative study of Artificial Bee Colony algorithm," Applied Mathematics and Computation, vol. 214, no. 1, pp. 108-132, 2009, doi: 10.1016/j.amc.2009.03.090

[23] B. Akay and D. Karaboga, "A modified Artificial Bee Colony algorithm for real-parameter optimization," Information Sciences, vol. 192, pp. 120-142, 2012, doi: 10.1016/j.ins.2010.07.015.

[24] A. Banharnsakun, T. Achalakul, and B. inaovakul, "The best-so-far selection in Artificial Bee Colony algorithm," Applied Soft Computing, vol. 11, no. 2, pp. 2888-2901, 2011, doi: 10.1016/j.asoc.2010.11.025.

[25] W. Gao and S. Liu, "Improved artificial bee colony algorithm for global optimization," Information Processing Letters, vol. 111, no. 17 , pp. 871-882, 2011.

[26] H. Bouyghf, B. Benhala, and A. Raihani, "Artificial bee colony technique for a study of the influence of impact of metal thickness on the factor of quality-Q in integrated square spiral inductors," 4th International Conference on Optimization and Applications (ICOA 18), April 2627, 2018, doi: 10.1109/ICOA.2018.8370503.

[27] H. Bouyghf, B. Benhala, and A. Raihani, "Optimization of 60-GHZ down-converting CMOS dual-gate mixer using artificial bee colony algorithm," Journal of Theoretical and Applied Information Technology, vol. 95, no. 4, pp. 890-902, 2017.

[28] D. S. Masmoudi, S. B. Salem, M. Loulou, and L. Kamoun, "A radio frequency CMOS current controlled oscillator based on a new low parasitic resistance CCII," International Conference on Electrical, Electronic and Computer Engineering, 2004, pp. 563-566, doi: 10.1109/ICEEC.2004.1374532

[29] S. Maheshwari, "High CMRR wide bandwidth instrumentation amplifier using current controlled conveyors," International Journal of Electronics, vol. 89, pp. 889-896, 2003, doi: 10.1080/0020721031000120452.

[30] Y. H. Ghallab, W. Badawy, K. V. I. S. Kaler, and B. J. Maundy, "A novel current-mode instrumentation amplifier based on operational floating current conveyor," IEEE Transactions on Instrumentation and Measurement, vol. 54, pp. 1941-1949, 2005, doi: 10.1109/TIM.2005.854254

\section{BIOGRAPHIES OF AUTHORS}

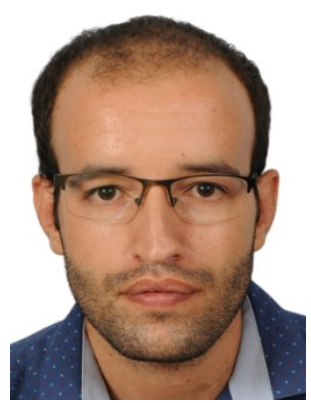

Issa Sabiri (iD 81 SC P was born in Msemrir, Morocco on April 18, 1995. In 2016 he had got his license degree in Bio Medical Instrumentation \& Maintenance, at the institute of health sciences Settat-Morocco (ISSS) at the University Hassan I Settat-Morocco, then he had got a Master's degree in biomedical engineering from FST Settat in 2018. He is currently a PhD student in the Laboratory of Systems, Signals and Artificial Intelligence, (LSSDIA) Hassan II University, Mohammedia-Casablanca, Morocco. His works studies and interests are focused on Development, Design and Optimization of electronic systems for biomedical engineering and health sciences. He can be contacted at email: issa.sabiri@etu.fstm.ac.ma. 


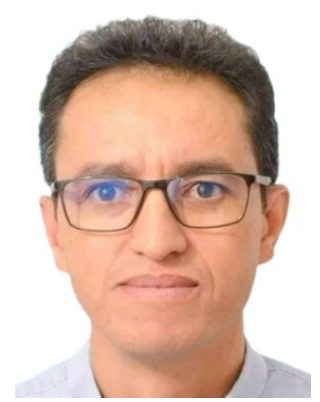

Hamid Bouyghf (iD IS SC P was born in Errachidia, Morocco in 1982. He received the B.S. and M.S. degrees in Electrical Engineering and Telecom from the University of Science and Technology, Fez, Morocco, in 2007 and the Ph.D. degree in Electrical Engineering \& Telecom from Faculty of Science and technic - Mohammedia, Hassan II University of Casablanca, Morocco, in 2019. From 2015 to 2019, he was a Research Assistant with the Princeton Plasma Physics Laboratory. Since 2019, he has been an Assistant Professor with the Electrical Engineering Department, FST Mohammedia, Hassan II University, Casablanca, Morocco. He is the author of more articles in optimization of ICs area. His research interests include electronic applied to biomedical domain and analog ICs design, electromagnetic field, low power design, and BLE applications. He can be contacted at email: hamid.bouyghf@fstm.ac.ma.

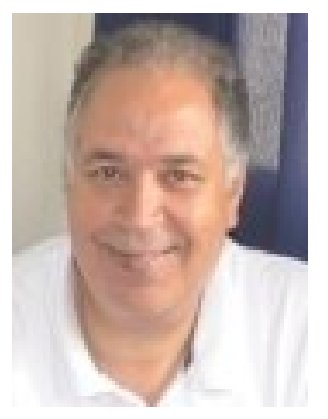

Abdelhadi Raihani (D) 881 SC P was born in 1968 at El Jadida, Morocco. He was appointed as a professor in Electronics Engineering at Hassan II University of Casablanca, ENSET Institute, Mohammedia Morocco since 1991. He received the B.S. degree in Electronics in 1987 and the M.S. degree in Applied Electronics in 1991 from the ENSET Institute. He has his DEA diploma in Information Processing from the Ben M'sik University of Casablanca in 1994. He received the Ph.D. in Parallel Architectures Application and image processing from the Ain Chock University of Casablanca in 1998. His current research interests are in the medical image processing areas, electrical engineering fields, particularly in renewable energy, energy management systems, power and energy systems control. He has more than 46 journal publications and over than 60 international conference papers. He is an active member in national research programs with IRESEN under the grant "Green INNO Project/ UPISREE". He supervised several PhD and Engineers students in these topics. He can be contacted at email: abraihani@yahoo.fr.

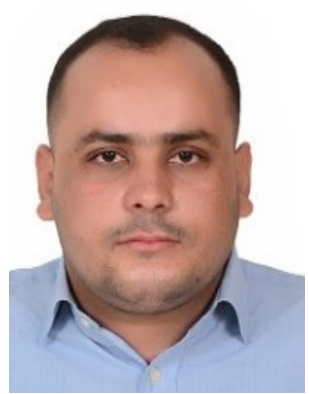

Brahim Ouacha (D) 8I SC P born in ghallil-taghzoute, Morocco on January 04, 1997. In 2018 he had got his license degree in physical science for the engineer, at the University Moulay Ismail Errachidia-Morocco (FSTE), then he had got a Master's degree in Electronic and Embedded System always in the same faculty. He is currently a Ph.D. student in the Laboratory of Electronics, Energy, Automatics and Data Processing (EEA\&TI) Hassan II University, Mohammedia-Casablanca, Morocco. His works studies and interests are focused on the design and optimization of wireless energy transfer systems, under the supervision of Pr. M. NAHID, Professor in Electrical Engineering department at the same University. He can be contacted at email: brahim.ouacha-etu@etu.univh2c.ma. 